\title{
Scimitar syndrome
}

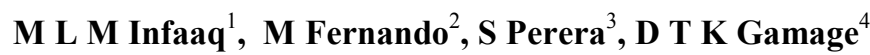

Sri Lanka Journal of Child Health, 2013; 42(2): 103-104

(Key word: scimitar syndrome)

\section{Introduction}

Scimitar syndrome is a rare congenital anomaly, characterized by partial or complete anomalous pulmonary venous drainage of the right or left lung into the inferior vena cava ${ }^{1}$. Because the radiographic shadow of the anomalous vein resembles a curved Turkish sabre, this defect has been named the "scimitar deformity".

\section{Case report}

An 8 year old boy presented to ward 2, Colombo North Teaching Hospital, with a history of lower respiratory tract infection and 3 episodes of

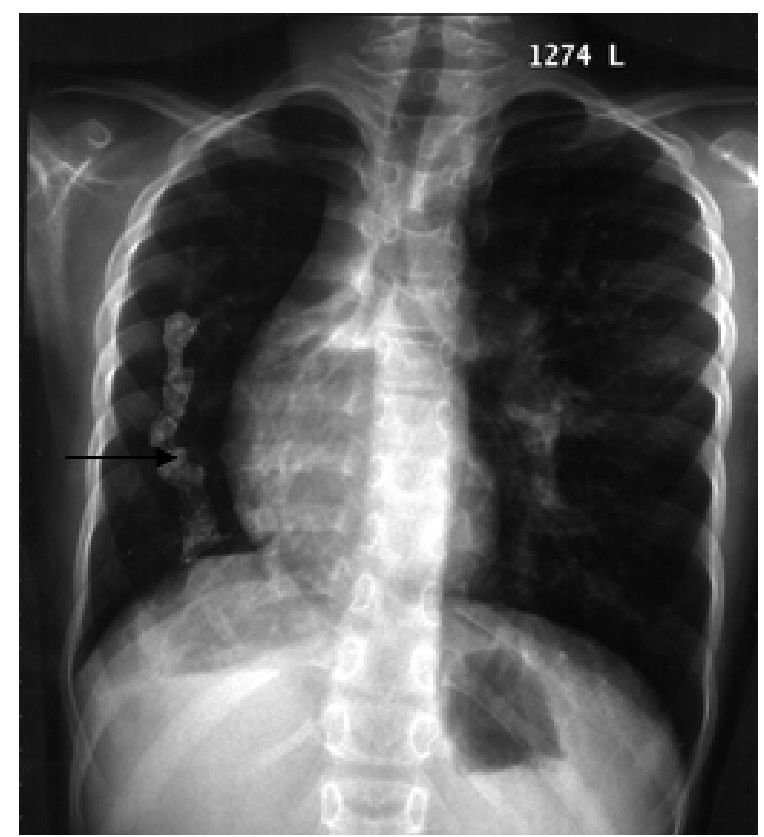

Figure 1: Chest X-ray (Scimitar vein shown by arrow)

\footnotetext{
${ }^{1}$ Registrar in Paediatrics Colombo North Teaching Hospital, ${ }^{2}$ Consultant Paediatrician Colombo North Teaching Hospital, ${ }^{3}$ Consultant Paediatric Cardiologist Lady Ridgeway Hospital, ${ }^{4}$ Registrar in Radiology Colombo North Teaching Hospital.
}

(Received on 20 September 2012: Accepted after revision on 19 October 2012) 


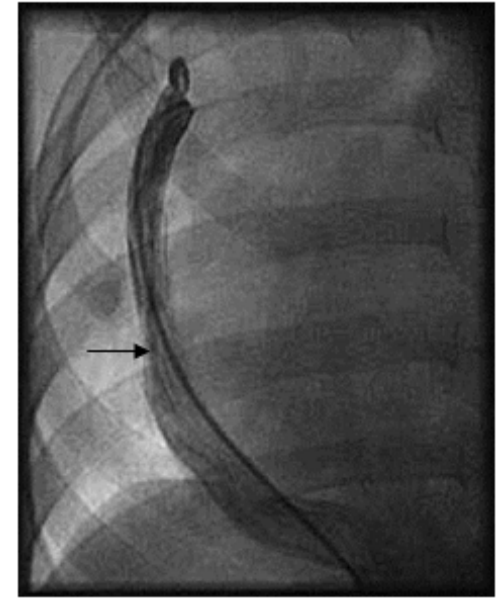

Figure 3: Angiogram of scimitar vein.

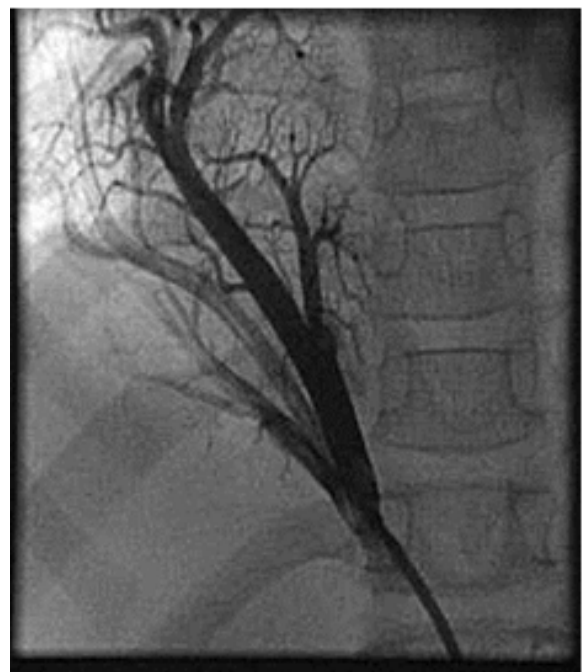

Figure 4: Angiogram of systemic pulmonary collaterals

As CT showed mild hypoplastic right lung, it was planned for direction of scimitar vein to left atrium and not right pneumonectomy. Our patient successfully underwent trans-catheter occlusion of systemic to pulmonary collaterals, using multiple embolization coils and is awaiting re-routing of scimitar vein to left atrium.

\section{Discussion}

Scimitar syndrome is commonly associated with hypoplasia of the right lung, pulmonary sequestration, persisting left superior vena cava, and dextroposition of the heart ${ }^{2}$. The pathogenesis of the syndrome is unclear, but it seems to originate from a basic developmental disorder of the entire lung bud early in embryogenesis ${ }^{2}$. Two main forms of scimitar syndrome have been described. Signs and symptoms can start during infancy (infantile form) or beyond (childhood/adult form). The infantile form generally presents within the first 2 months of life with tachypnea, recurrent pneumonia, failure to thrive, and signs of heart failure ${ }^{2}$. The diagnosis of scimitar syndrome is usually made based on the characteristic chest X-ray films and can be confirmed by angiography ${ }^{2}$. In the chest $x$-ray, a diagnostic vertically directed crescent shadow (scimitar sign) is observed to the right of the mediastinal silhouette $^{3}$.Cardiac dextroposition was present in our patient and the chest $\mathrm{x}$-ray and the scimitar sign was present in the chest $\mathrm{X}$-ray (Figure 1).

Asymptomatic patients in the absence of associated abnormalities can be followed up conservatively. For symptomatic patients, pulmonary: systemic blood flow (Qp: Qs) ratio greater than 1.5 and pulmonary hypertension require rerouting of anomalous right pulmonary veins to left atrium in order to avoid progression of right ventricular failure and it may require occlusion of systemic to pulmonary collaterals to reduce left to right shunt and thereby prevent any complications until corrective surgery ${ }^{1}$. The presence of haemoptysis is likely to be secondary to an anomalous systemic arterial blood supply to lung and it may warrant trans-catheter occlusion of the anomalous feeding arterial vessels ${ }^{4}$. This was done in our patient.

The triad of respiratory distress, right lung hypoplasia and dextroposition of the heart should alert the clinician to think of scimitar syndrome.

\section{References}

1. Demir E, Aşkın M, Midyat L, Gülen F, Ülger Z. Eponym scimitar syndrome. European Journal of Pediatrics 2010; 169 (10): 1171-7. http://dx.doi.org/10.1007/s00431-010-1152-4

2. Najm HK, Williams WG, Coles JG, Rebeyk JM, Freedom RM. Scimitar Syndrome: twenty year experience and results of repair: Journal of Thoracic and Cardiovascular Surgery 1996; 112: 1161-9. http://dx.doi.org/10.1016/S0022-5223(96)70129$\underline{0}$

3. Crillio RL. The scimitar sign. Radiology 1998; 206: $623-4$.

4. Nedelcu C, Carette M, Parrot A, Hammoudi N, Marsault C. Haemoptysis complicating scimitar syndrome: from diagnosis to treatment. Cardiovascular and Interventional Radiology 2008; 31 (suppl 2); S96-8. http://dx.doi.org/10.1007/s00270-007-9162-y 